\title{
Determination of sulfonamide compounds in sewage and river by mixed hemimicelles solid-phase extraction prior to liquid chromatography-spectrophotometry
}

\author{
Ji-Dong Li ${ }^{\text {a,b }}$, Ya-Qi Cai ${ }^{\text {a,* }}$, Ya-Li Shi ${ }^{\text {a }}$, Shi-Feng Mou ${ }^{\text {a }}$, Gui-Bin Jiang ${ }^{\text {a }}$ \\ a State Key Laboratory of Environmental Chemistry and Ecotoxicology, Research Center for Eco-Environmental Sciences, \\ Chinese Academy of Sciences, Beijing 100085, China \\ ${ }^{\mathrm{b}}$ General Research Institute for Non-ferrous Metals, Beijing 100088, China
}

Received 21 July 2006; received in revised form 16 October 2006; accepted 8 November 2006

Available online 29 November 2006

\begin{abstract}
Mixed hemimicelles-based solid-phase extraction was investigated for the preconcentration of five sulfonamides from environmental water samples prior to HPLC-spectrophotometry determination in this paper. A comparative study on the use of sodium dodecyl sulfate (SDS) coating $\gamma$-alumina or octadecyltrimethylammonium bromide (OTMABr) and OTMABr coating silica as sorbent materials were presented. The five analytes (sulfadiazine (SDA), sulfathiazole (STA), sulfapyridine (SPD), sulfamethazine (SMZ) and sulfamethoxazole (SMX)) were quantitatively adsorbed on OTMABr- $\gamma$-alumina and OTMABr-silica mixed hemimicelles, but OTMABr- $\gamma$-alumina was not adopted because it worked at a high pH (around 10), instead, OTMABr-silica was selected to overcoming the $\mathrm{pH}$ restriction. The analytes retained on the cartridge were quantitatively desorbed with suitable amounts of methanol. Factors influencing the extraction efficiency, such as the amount of surfactant, $\mathrm{pH}$ of sample and breakthrough volume were discussed. The proposed method had been applied to determining the five sulfonamides in several environmental water samples and concentration factors of 300 and 600 for SDA and other four analytes were achieved, respectively. Detection limits obtained ranged between 0.15 and $0.35 \mu \mathrm{g} / \mathrm{L}$ for this five sulfonamides under the optimized conditions. The accuracy of the method was evaluated by recovery measurements on spiked samples, and good recovery results (89-113\%) with precision of 3-6\% were achieved.
\end{abstract}

(C) 2006 Elsevier B.V. All rights reserved.

Keywords: Mixed hemimicelles; Solid-phase extraction; Sulfonamides; LC-spectrophotometry

\section{Introduction}

Sulfonamides are widely used as a kind of antibacterial drugs in medical and veterinary applications, they are often prescribed for treatment of many human and animal infectious diseases $[1,2]$. Long-term use of the sulfonamides can result in serious side effects [3]. As a result, sulfonamides can be found in excreta of animal origin. These compounds can be leached from the above-mentioned substances and released into various environments through wastewater, and therefore, they are ubiquitous in various environmental matrices. Europe and Japan for instance

\footnotetext{
* Corresponding author at: Chinese Academy of Sciences, Research Center for Eco-Environmental Sciences, P.O. Box 2871, Beijing 100085, China. Tel.: +86010 62849182; fax: +8601062849239.

E-mail address: Caiyaqi@ rcees.ac.cn (Y.-Q. Cai).
}

have acted the maximum residue levels of 100 and $20 \mathrm{ng} / \mathrm{g}$ in edible tissues and milk, respectively, referring to the sum of sulfonamides [4,5]. All these limits will be lowered based on improvement of analytical methods.

The concentration of sulfonamides is low (usually ppb level) in aqueous environmental samples and the environmental matrices composition is also complex, which make it difficult to determine these compounds directly and the use of preconcentration methods and clean steps prior to their analysis become necessary. Several papers have discussed the different methods of sample preparation, chromatographic separation and detection systems used in the analysis of sulfonamides [6-10]. Stoob et al. [7] applied online solid-phase extraction coupled directly to liquid chromatography-tandem mass spectrometry to determining 10 sulfonamides in surface waters, the detection limits were between 0.5 and $5 \mathrm{ng} / \mathrm{L}$. Malintan et al. [10] applied SPE method to determining eight sulfonamides in wasterwater with 
HPLC separation and UV absorbance detection, the limit of quantitation (LOQ) were between 5 and $7.5 \mathrm{ng} / \mathrm{L}$. A number of other methods were described in literature including electrochemistry [11-13], spectrophotometric [14-16], ELISA [8,17] and MS $[18,19]$ detection.

Solid-phase extraction (SPE) at present was the most popular sample preparation method and was commonly used for a wide range of compounds prior to LC analysis. It has many obvious advantages compared with liquid-liquid extraction, such as high preconcentration factors, low consumption of organic solvents and easy to operate. Hemimicelles and admicelles (mixed hemimicelles) have been recently emerged as excellent sorbent materials for the SPE of organic compounds [20-22]. These sorbent materials are produced by the adsorption of ionic surfactants on the surface of metal oxides, such as alumina, silica, and ferric oxyhydroxides. Generally, ionic surfactant adsorbed onto metal oxides can be divided into four steps [23-25]. In the first step adsorption of surfactant on metal oxides occurs through coulombic attraction between charged oxide surface and the oppositely charged surfactant head group (Henry's law zone), this one-toone charge exchange of surfactant and adsorbed counter ions does not greatly change the charge of the solid particle. The second step involves strong lateral interaction between adsorbed monomers, resulting in the formation of primary aggregates, known as hemimicelles and this association greatly enhances the adsorption capability of the solid particle. The adsorption is thus driven both by hydrophobic interactions and electrostatic attraction, which results in the formation of both hemimicelles and admicelles (mixed hemimicelles). At the end of the step surfactant forms micelles in solution, the overall surface charge is neutralized and further adsorption is purely due to hydrophobic interactions with the surfactant tails. The process of solubilization of organic compounds in mixed hemimicelles is termed as "adsolubilization".

Mixed hemimicelles used in SPE have many advantages, such as high extraction yields, high breakthrough volumes, easy elution of analytes and high flow rate for sample loading. On the other hand, this kind of SPE technique requires no clean-up steps and easy and simple to regenerate, which can meet the need of rapid analysis. Furthermore, there are many kinds of surfactant available in commerce and it is easy to select a suitable surfactant as sorbent according to various environmental samples. These characteristics make mixed hemimicelles have a great potential for the SPE of organic compounds.

The objective of this work was to develop a simple and rapid approach for determining five sulfonamides at trace levels existed in sewage and river water and apply the SPE method based on mixed hemimicelles to concentrate these compounds. Mixed hemimicelles prepared by adsorption of SDS on $\gamma$-alumina and OTMABr on silica and $\gamma$-alumina were tried. Predominant experimental factors affecting the forming of mixed hemimicelles and the recoveries for these five sulfonamides were studied. The results of analyzing the target compounds in sewage and river samples using this technique were proven to be dependable and the analytical method of the SPE-LC-spectrophotometry based on OTMABr-silica was established. To our knowledge adsolubilizaton-based SPE for the treatment of sulfonamides in sewage and river water samples was the first reported.

\section{Experimental}

\subsection{Chemicals and materials}

All reagents were of analytical grade and were used as supplied. Five sulfonamides were obtained from Sigma-Aldrich (USA) and their structure was listed in Table 1. A stock solution containing $200 \mathrm{mg} / \mathrm{l}$ each sulfonamide was prepared in methanol and stored under dark conditions at $4{ }^{\circ} \mathrm{C}$. The surfactants SDS and OTMABr were supplied by Shanghai Reagent Corporation (Shanghai, China). Alumina ( $\gamma$-form) and silica were supplied by Sigma-Aldrich (USA). The physical properties of these two metal oxides were as follows: alumina-surface area $\left(155 \mathrm{~m}^{2} / \mathrm{g}\right)$; point of zero charge (pcz, 8.5); particle diameter range (50-200 $\mu \mathrm{m}$, mean value $100 \mu \mathrm{m})$, mean pore size (58 $\mathrm{A})$; density $\left(3.97 \mathrm{~g} / \mathrm{cm}^{3}\right)$. Silica-surface area $\left(300 \mathrm{~m}^{2} / \mathrm{g}\right)$; point of zero charge (pcz, 2.9); particle diameter range $(70-150 \mu \mathrm{m})$, mean pore size $(150 \AA)$; density $\left(1.15 \mathrm{~cm}^{3} / \mathrm{g}\right)$. HPLC-grade acetonitrile and methanol were supplied by Merck (Germany). Water used in all of the experiments was prepared using a compact ultrapure water system from Barnstead (Iowa, USA).

\subsection{Sample collection}

All water samples were collected from different district in Beijing. Influent and effluent wastewater samples were collected from Gaobeidian sewage treatment plants (Chaoyang district). Gaobeidian sewage treatment plant lies in the east of Beijing and it receives about the same level of domestic and industrial wastewater. The main applied treatment process was as follows:

Influent sewage $\rightarrow$ Filtrated through bar screen

$\rightarrow$ Aerated grit channel $\rightarrow$ Primary precipitation

$\rightarrow$ Aeration basin $\rightarrow$ Second precipitation

$\rightarrow$ Secondary effluent water.

River water samples were taken from Small Qing River (Haidian district) and Jingmi Canal (Haidian district) in June 2006. Tap water samples were taken from our lab in Haidian district. All water samples were collected randomly. Samples were collected into pre-cleaned, light-preserved glass bottles and filtered through $0.22 \mu \mathrm{m}$ nylon membranes (Shanghai Institute of Pharmaceutical Industry, China) in order to remove suspended solids, then adjusted to $\mathrm{pH} 2$ with $1 \mathrm{M} \mathrm{HNO}_{3}$. The filtered samples were stored at $4{ }^{\circ} \mathrm{C}$.

\subsection{SPE based on mixed hemimicelles}

A mixed hemimicelles-packed cartridge was prepared by modifying a Supelco ENVI-Carb (Supelco, USA) SPE Tubes $(0.5 \mathrm{~g}, 6 \mathrm{~mL}$, polypropylene). The active carbon packing of the cartridge was evacuated, and then $0.5 \mathrm{~g}$ silica was packed into the cartridge. 
Table 1

Chemical structures, pKa and $\log K_{\mathrm{o} / \mathrm{w}}$ value of the five sulfonamide compounds

\begin{tabular}{|c|c|c|c|c|}
\hline Name & Abbreviation & Structure & $\mathrm{p} K \mathrm{a}$ & $\log K_{\mathrm{o} / \mathrm{w}}$ \\
\hline Sulfathiazole & STA & $\mathrm{H}_{2} \mathrm{~N}^{-}$ & 7.1 & 1.01 \\
\hline Sulfamethazine & SMZ & 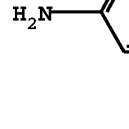 & 7.4 & 0.87 \\
\hline Sulfamethoxazole & SMX & & 6.0 & 0.92 \\
\hline
\end{tabular}

To prepare mixed hemimicelles column, 25 ml-containing $160 \mathrm{mg}$ of OTMABr was passed through the cartridge column filled with $0.5 \mathrm{~g}$ silica. The water samples was adjusted to $\mathrm{pH}$ 6 and loaded into the column. Sample loading was performed by using a DOA-PIOU-BN vacuum pump (Mich., USA) at a flow rate of $5 \mathrm{ml} / \mathrm{min}$. Target analytes were eluted with $4.0 \mathrm{ml}$ methanol and the eluate was dried with a stream of nitrogen at $60{ }^{\circ} \mathrm{C}$, and then dissolved in $0.5 \mathrm{ml}$ methanol. The solution was stirred in an ultrasonic bath for $5 \mathrm{~min}$ and a $20-\mu \mathrm{l}$ of the eluate was injected into the HPLC system for analysis.

\subsection{HPLC analysis}

The sulfonamides were separated and quantified by using a liquid chromatography-spectrophotometry system (P680 HPLC Pump with an AD25 Absorbance Detector, Dianox, USA). The analytical column was a $250 \mathrm{~mm}$ Diamonsil- $\mathrm{C}_{18}$ column ( $4 \mu \mathrm{m}$ particle diameter and $4.6 \mathrm{~mm}$ i.d.) supplied by Dikma Technologies (Beijing, China). The mobile phase consisted of water (the $\mathrm{pH}$ was adjusted to 3 with $\mathrm{H}_{3} \mathrm{PO}_{4}$, solvent $\mathrm{A}$ ) and acetonitrile-water (acetonitrile:water, 75:25, v/v, solvent $\mathrm{B}$ ). The gradient elution program was as follows: isocratic conditions with $85 \% \mathrm{~A}: 15 \% \mathrm{~B}$ for $5 \mathrm{~min}$ and then linear gradient from 15 to $40 \% \mathrm{~B}$ in $10 \mathrm{~min}$, keep for $10 \mathrm{~min}$ then linear gradient from 40 to $15 \% \mathrm{~B}$ in $3 \mathrm{~min}$. The flow rate was set at $1 \mathrm{ml} / \mathrm{min}$. Spectrophotometry detection of analytes was performed at $260 \mathrm{~nm}$

\section{Results and discussion}

\subsection{The protonation and ionization of sulfonamides}

The general structure of sulfonamide is as follows:<smiles>[R]NS(=O)(=O)c1ccc(N)cc1</smiles>

the five sulfonamides in this paper can be distinguished by the different $-R$ group, which were shown in Table 1 . In acidic $\mathrm{pH}$ range sulfonamide compounds become protonated via $-\mathrm{NH}_{2}$ group and have positive charge, while sulfonamide begins to ion- 
ize at the $\mathrm{pH}$ nearer to their $\mathrm{pKa}$ value and have negative charge. However, sulfonamides still have great hydrophobic function due to the phenyl group.

\subsection{Effect of the amount of surfactant}

The effect of the amount of surfactant on the adsolubilization of sulfonamides was studied in batch mode and the experiments were carried out as follows: a aqueous solution containing 0-240 mg SDS/g alumina ( $\mathrm{pH}=2), 0-240 \mathrm{mg}$ OTMABr/g alumina $(\mathrm{pH}=10)$ or $0-880 \mathrm{mg}$ OTMABr/g silica $(\mathrm{pH}=6)$ was added to an aqueous suspension of $0.5 \mathrm{~g} \gamma$-alumina or silica, respectively. The solution $\mathrm{pH}$ was adjusted with $1.0 \mathrm{M}$ $\mathrm{NaOH}$ and $\mathrm{HNO}_{3}$. To the mixed hemimicelles system, $0.5 \mathrm{ml}$ containing $200 \mathrm{mg} / \mathrm{l}$ each sulfonamide solution were added. Total volume of the solution system was $25 \mathrm{ml}$ in a $250 \mathrm{ml}$ glass vial with a cap. All the equilibrium was carried out at $25 \pm 1{ }^{\circ} \mathrm{C}$ temperature in a water bath with 5 min vigorous stirring. Then the solids were separated by filtering through $0.22 \mu \mathrm{m}$ nylon membranes and the supernatant was analyzed using HPLC-spectrophotometry.

The experimental results were shown in Fig. 1. As can be seen from Fig. 1(A) that with the increasing amount of SDS the adsorption extent of sulfonamides had no obvious changing trend and sulfonamides hardly sorbed onto the SDS$\gamma$-alumina mixed hemimicelles. According to the literature $[20,21]$, the SDS- $\gamma$-alumina at $\mathrm{pH} 2$ should form mixed hemimicelles easily and have a great potential to sorb hydrophobic compounds. However, the experimental results were opposite, which may be explained that at the condition $\mathrm{pH} 2$ the sulfonamides were protonated and had positive charge, then a repelling force would produce between the sulfonamides and alumina surface with positive charge. Furthermore, this repelling func- tion plays a more important role compared with hydrophobic function. The Fig. 1(B, C) described that with the increasing amount of OTMABr, the sorption amount increased remarkably then decreased when the added amount of OTMAB exceeded $60 \mathrm{mg}$ for alumina and $200 \mathrm{mg}$ for silica, respectively. The increase in sorption can be explained by the gradual formation of hydrophobic mixed hemimicelles on the surface of $\gamma$-alumina and silica, maximum sorption were obtained in the range of 30-60 mg SDS and 100-200 mg OTMABr, respectively. The main difference was the adsorption percentage of SDA, which was about 40 and $80 \%$ for $\gamma$-alumina and silica, respectively. The decrease in sorption was due to the reason that with more surfactant added the SDS and OTMAB molecules began to form micelles in the bulk aqueous solution, furthermore, the micelles made the sulfonamides distribute into the solution again. For the OTMABr-alumina system, the sulfonamides had deprotonated and the surface of alumina was negative charged under $\mathrm{pH} 10$ conditions; similarly, for the OTMABr-silica system the sulfonamides had protonated and the surface of silica was positive charged under $\mathrm{pH} 6$ conditions, so a repelling force should exist in two systems. However, Fig. 1(B, C) showed that the two system both had strong adsorption ability for the sulfonamide compounds, which can be explained that the hydrophobic interactions between the sulfonamides and formed mixed hemimicelles governed the retention of analytes under the experimental conditions. $\log K_{\mathrm{o} / \mathrm{w}}$ was used extensively to demonstrate compound hydrophobic properties and Table 1 listed the $\log K_{\mathrm{o} / \mathrm{w}}$ of the five sulfonamides. Fig. 1(B, C) also showed that the different sorption amount of the five sulfonamides appeared to be closely correlated with $\log K_{\mathrm{o} / \mathrm{w}}$, which also proved that the extractability of sulfonamides mainly depended on the hydrophobic properties of the analytes.
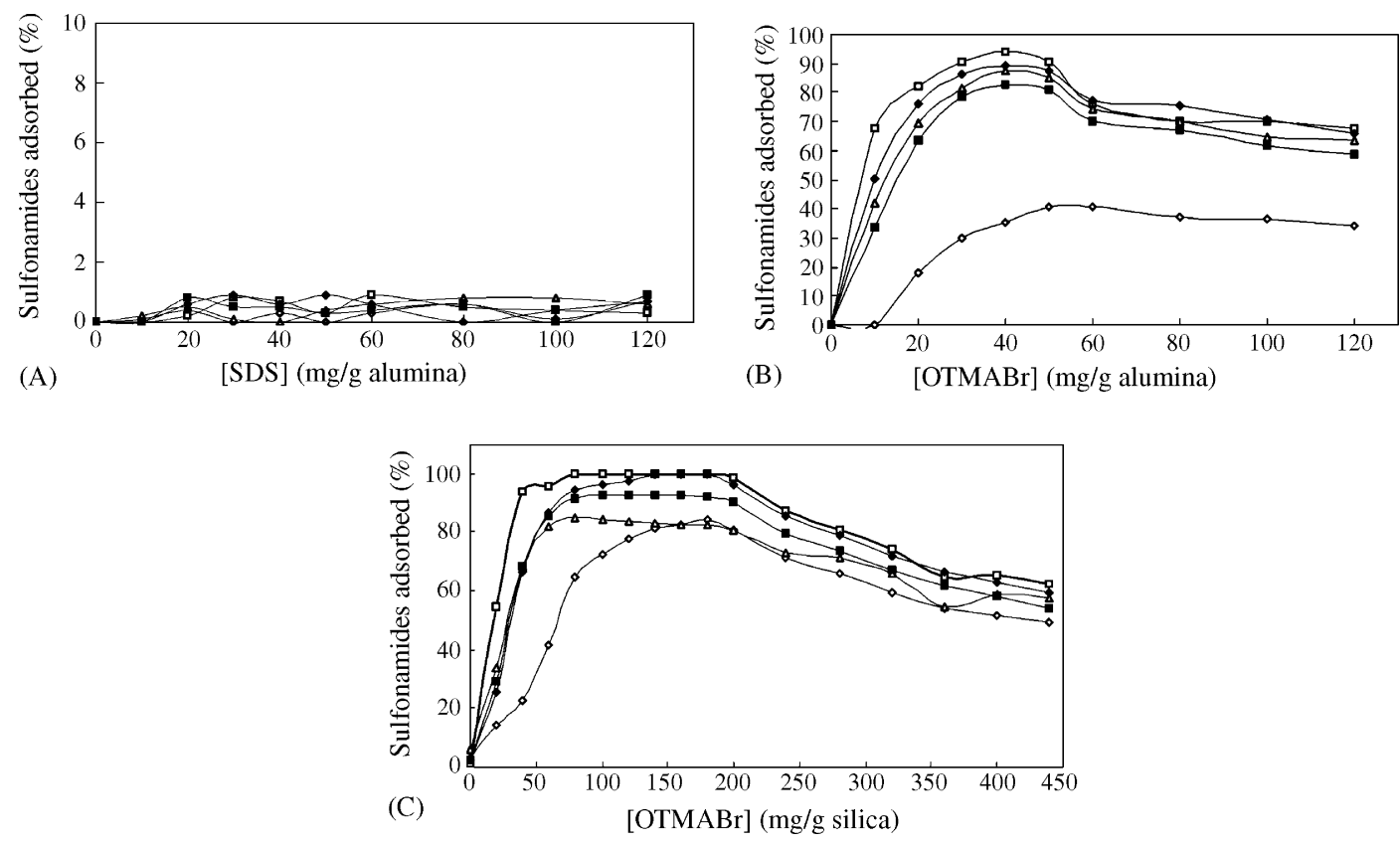

Fig. 1. Effect of the amount of (A) SDS, (B) OTMABr mixed hemimicelles formed on alumina and (C) OTMABr mixed hemimicelles formed on silica for the adsolubilization of sulfonamides: $(\diamond)$ SDA, $(\square)$ STA, $(\triangle)$ SPD, $(\square)$ SMZ and $(\diamond)$ SMX. pH: (A) 2, (B) 10 and (C) 6. 

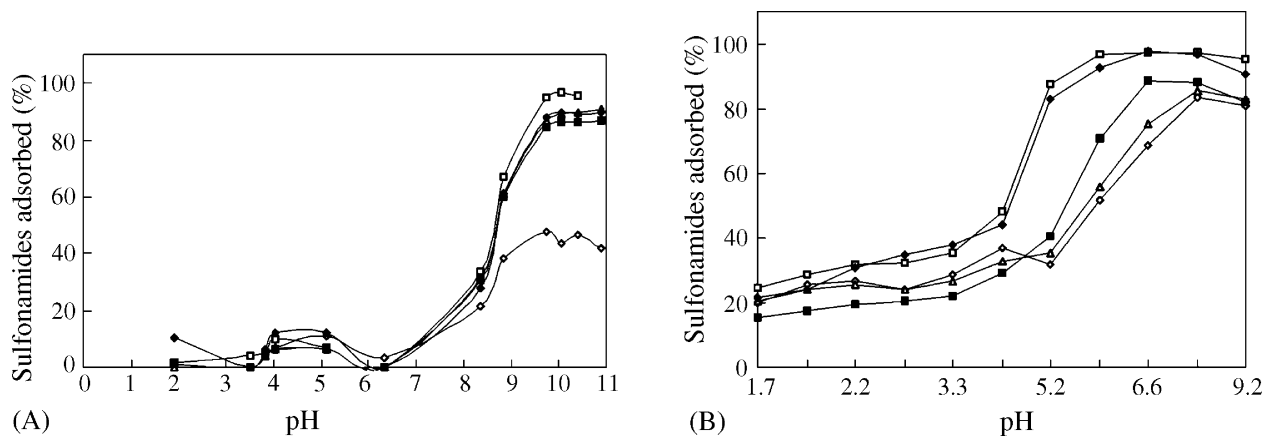

Fig. 2. Influence of $\mathrm{pH}$ on the adsorption of sulfonamides: $(\diamond) \mathrm{SDA},(\square) \mathrm{STA},(\triangle) \mathrm{SPD}$ alumina and (B) OTMABr-silica.

\subsection{Effect of the $p H$}

The $\mathrm{pH}$ of the solution was one of the prime factors that drastically influenced the adsorption behavior of the mixed hemimicelles system. In the present study, the effect of $\mathrm{pH}$ had been observed by varying the $\mathrm{pH}$ in the range $1.7-11$. The experiments were carried out in batch mode above-mentioned in Section 3.2. The selected amount of OTMABr for alumina and silica was 40 and $160 \mathrm{mg}$, respectively. As can be seen from Fig. 2 that the $\mathrm{pH}$ did not affect the adsorption amount of sulfonamides obviously by OTMABr- $\gamma$-alumina in the range of $2-8$ and by OTMABr-silica in the range of 1.7-3.3, while when the $\mathrm{pH}$ up to 8 for alumina and 3.3 for silica, the sorption amounts both increased dramatically. The significant increase can be ascribed to the formation of mixed hemimicelles on the surface of metal oxide when $\mathrm{pH}$ was above the pcz value of alumina and silica, respectively. The Fig. 2(A) also demonstrated that SDA still had poorer sorption percentage of about $40 \%$ than that of $80 \%$ in Fig. 2(B).

According to above experimental results, SPE ofsulfonamides based on OTMABr- $\gamma$-alumina mixed hemimicelles system needs high $\mathrm{pH}$ value ( $\mathrm{pH} 10)$, which may lead to some depositions in wastewater, furthermore, the sorption efficiency of SDA was poor. So, we selected the OTMABr-silica mixed hemimicelles as sorbent to carry out next experiments.

\subsection{Breakthrough volume and desorption}

The breakthrough volume for each sulfonamide on OTMABr-silica sorbent was determined through passing increasing volume $(50-500 \mathrm{ml})$ of influent wastewater sample spiked with $1 \mu \mathrm{g}$ of each sulfonamide at $\mathrm{pH} 6$. The cartridge was filled with $500 \mathrm{mg}$ silica and loaded with solution containing $160 \mathrm{mg}$ OTMABr, then determining the recovery of each sulfonamide. Breakthrough was considered to occur when the recovery was below $95 \%$. It was found to be $150 \mathrm{ml}$ for SDA and $300 \mathrm{ml}$ for the other four sulfonamides. By drying the eluate with a nitrogen flow and redissolving the analytes in $0.5 \mathrm{ml}$ methanol, the preconcentration factors of 300 for SDA and 600 for STA, SPD, SMZ and SMX were achieved, respectively. The sample flow rate experiments $(1-10 \mathrm{ml} / \mathrm{min})$ were carried out using deionized water spiked with $1 \mu \mathrm{g}$ of each sulfonamide under the selected breakthrough volume. Flow rate was considered too fast when recovery of the eluate was below $95 \%$. The experimental results indicated that the recoveries were all above $95 \%$ when sample rate was in the range of $1-5 \mathrm{ml} / \mathrm{min}$; when sample rate increased to 8 and $10 \mathrm{~m} / \mathrm{min}$, the recoveries of SDA was reduced to 80 and $60 \%$ and that of the four other sulfonamides were reduced to 85 and $70 \%$, respectively.

Desorption of sulfonamides from the OTMABr-silica mixed hemimicelles column was studied with different organic solvents (acetonitrile, methanol) and $0.01 \mathrm{M} \mathrm{HNO}_{3}$. Quantitative recoveries of sulfonamides were obtained using $4 \mathrm{ml}$ methanol. When using $4 \mathrm{ml}$ acetonitrile, the recoveries were $70,85,89,86$ and $81 \%$ for SDA, STA, SPD, SMZ and SMX, respectively. Higher volume acetonitrile $(8 \mathrm{ml})$ was required for eluting sulfonamides completely. When using $4 \mathrm{ml} 0.01 \mathrm{M} \mathrm{HNO}_{3}$, the recoveries were $57,68,69,84$ and $82 \%$ for SDA, STA, SPD, SMZ and SMX, respectively. Thus, $4 \mathrm{ml}$ methanol was recommended for elution.

\subsection{Analytical performance}

Calibration curves were run using 150 and $300 \mathrm{ml}$ deionized water for SDA and four other sulfonamides both spiked with $0.3-30 \mathrm{ng} / \mathrm{ml}$ sulfonamides, respectively. According to the overall SPE procedure and HPLC analysis method abovementioned, the calibration curves were established. The slope of the calibration curves was $129.6 \pm 2.9,237.8 \pm 1.6,242.3 \pm 4.9$, $245.7 \pm 5.7$ and $287.6 \pm 3.5 \mathrm{ng}^{-1}$ with the correlation coefficients $(r)$ 0.996, 0.995, 0.997, 0.998, 0.991 for SDA, STA, SPD, SMZ and SMX, respectively. The correlation coefficients obtained indicated good fits for all sulfonamides in this method.

The practical detection limits were estimated using influent wastewater as a typical sample for it having the high BOD of $129 \mathrm{mg} / \mathrm{L}$ and the most complex matrix in the five collected water samples. As we determined the concentration of five sulfonamides in influent wastewater beforehand and found that the SDA and STA had no readout signals in spectrophotometer while the concentration of other three sulfonamides were between 0.35 and $0.64 \mu \mathrm{g} / \mathrm{L}$, so we spiked $0.50 \mu \mathrm{g} / \mathrm{L}$ SDA and STA into the influent wastewater, respectively, and used this water sample to evaluate the practical detection limits. The practical detection limits were evaluated from six independent overall determina- 
Table 2

Determination and recoveries of sulfonamides in real water samples

\begin{tabular}{|c|c|c|c|c|c|c|c|c|c|c|c|c|c|c|c|}
\hline \multirow[t]{2}{*}{ Samples } & \multicolumn{5}{|c|}{ Added $(\mu \mathrm{g} / \mathrm{L})$} & \multicolumn{5}{|c|}{ Founded $^{\mathrm{a}}(\mu \mathrm{g} / \mathrm{L})$} & \multicolumn{5}{|c|}{ Recovery $^{\mathrm{b}}(\%)$} \\
\hline & SDA & STA & SPD & SMZ & SMX & SDA & STA & SPD & SMZ & SMX & SDA & STA & SPD & SMZ & SMX \\
\hline Tap water & 0 & 0 & 0 & 0 & 0 & n.d. ${ }^{\mathrm{c}}$ & n.d. ${ }^{\mathrm{c}}$ & n.d. ${ }^{\mathrm{c}}$ & n.d. ${ }^{\mathrm{c}}$ & n.d. ${ }^{\mathrm{c}}$ & & & & & \\
\hline \multirow[t]{2}{*}{ Jingmi canal river } & 0 & 0 & 0 & 0 & 0 & n.d. ${ }^{\mathrm{c}}$ & n.d. ${ }^{\mathrm{c}}$ & n.d. ${ }^{\mathrm{c}}$ & n.d. ${ }^{\mathrm{c}}$ & n.d. ${ }^{\mathrm{c}}$ & & & & & \\
\hline & 0.3 & 0.3 & 0.3 & 0.3 & 0.3 & 0.27 & 0.29 & 0.31 & 0.29 & 0.30 & $90 \pm 5$ & $96 \pm 3$ & $102 \pm 5$ & $98 \pm 6$ & $101 \pm 3$ \\
\hline \multirow[t]{2}{*}{ Gaobeidian influent } & 0 & 0 & 0 & 0 & 0 & n.d. ${ }^{c}$ & 0.35 & n.d. ${ }^{\mathrm{c}}$ & 0.58 & 0.64 & & & & & \\
\hline & 0.3 & 0.3 & 0.3 & 0.3 & 0.3 & 0.27 & 0.67 & 0.28 & 0.84 & 0.96 & $91 \pm 5$ & $103 \pm 6$ & $96 \pm 5$ & $95 \pm 3$ & $103 \pm$ \\
\hline \multirow[t]{2}{*}{ Gaobeidian effluent } & 0 & 0 & 0 & 0 & 0 & n.d. ${ }^{\mathrm{c}}$ & n.d. ${ }^{\mathrm{c}}$ & n.d. ${ }^{\mathrm{c}}$ & n.d. ${ }^{\mathrm{c}}$ & 0.56 & & & & & \\
\hline & 0.3 & 0.3 & 0.3 & 0.3 & 0.3 & 0.27 & 0.29 & 0.32 & 0.31 & 0.84 & $89 \pm 5$ & $95 \pm 6$ & $105 \pm 5$ & $104 \pm 3$ & $99 \pm$ \\
\hline
\end{tabular}

${ }^{\text {a }}$ Mean of three determinations.

b Standard deviation for three determinations.

${ }^{\mathrm{c}}$ Not detected.

tion of sulfonamides concentration and calculated by using the standard deviation $\left(\mathrm{S}_{0}\right)$ of 3 [26]. The detection limits were 0.35 , $0.26,0.16,0.15$ and $0.15 \mu \mathrm{g} / \mathrm{L}$ for SDA, STA, SPD, SMZ and SMX, respectively. The precision was evaluated by six independent and continuous extractions of the influent wastewater samples spiked with $1 \mu \mathrm{g}$ of each sulfonamide. The relative standard deviation ranged from 3 to $6 \%$, which indicated the good precision of this method.

\subsection{Analysis of real water samples}

The proposed method was applied to the analysis of some real environmental water samples, and the experimental results are shown in Table 2. No sulfonamides were found in the tap and Jingmi canal river water. For the case of other three water samples, only STA, SMZ and SMX were found. The accuracy of this method was evaluated by the recovery test, which was carried
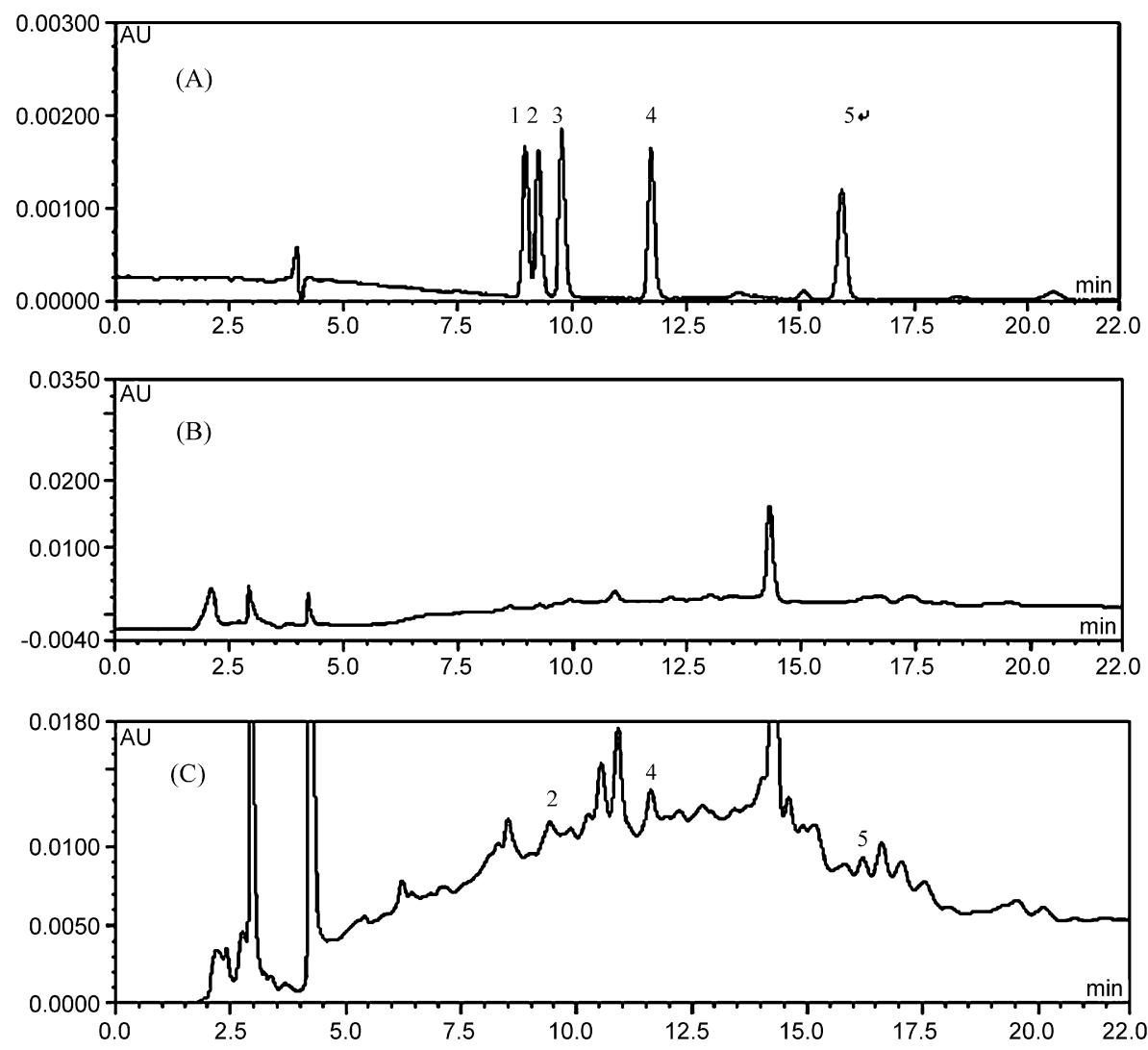

Fig. 3. Solid-phase extraction/LC-spectrophotometry chromatograms. (A) Standard solution containing $1 \mathrm{mg} / \mathrm{l}$ of each compound (B) Jinmi river water sample, and (C) influent wastewater sample. 1, SDA; 2, STA; 3, SPD; 4. SMZ; 5. SMX. 
out with standard sulfonamides mixture-spiked water samples. Recoveries ranged between 89 and $113 \%$ for five sulfonamides and the results are fairly satisfactory. The chromatograms of a river water sample and influent wastewater sample were shown in Fig. 3.

\section{Conclusions}

A simple, rapid and reliable method was developed for the solid-phase extraction of five sulfonamides in several environmental water samples by using a OTMABr-silica-packed cartridge. The use of mixed hemimicelles SPE technique was effective for concentrating traces of sulfonamides in water prior to HPLC analysis. The strong hydrophobic interactions between the surface of the mixed hemimicelles and sulfonamides resulted in their high retention, however, the analytes retained on OTMABr-silica can be easily desorbed with methanol and no carryover is observed in the next analysis. Good recoveries and precision of this method were obtained, which showed that OTMABr-silica SPE method have high analytical potential for preconcentration of other traces of organic pollutants from water samples.

\section{Acknowledgment}

This work was jointly supported by National Basic Research Program of China (2003CB415001); the National Natural Science Foundation of China $(20577058,20475060)$ and Major Research Program of Chinese Academy of Sciences (KZCX3SW-432).

\section{References}

[1] A.R. Long, L.C. Hsieh, M.S. Malbrough, C.R. Short, S.A. Barker, J. Agric. Food Chem. 38 (1990) 423.
[2] J. Marek, Farmakoterapie Vnitrnich Nemoci (Pharmacotherapy of Internal Diseases), Grada Publishing, Prague, 1998, p. 59.

[3] F. Xiong, H. Dai, Z.N. Yuan, Chin. J. Anal. Sci. 18 (2002) 415.

[4] EU Regulation, No. 508/1999, L60 (9-3-1999) 16.

[5] Food and Drug Regulation, Table III, Division 15, Part B, Canada Gazette Part II, 125,1478, 1991

[6] A. Gobel, C.S. McArdell, M.J.-F. Suter, W. Giger, Anal. Chem. 76 (2004) 4756.

[7] K. Stoob, H.P. Singer, C.W. Goetz, M. Ruff, S.R. Mueller, J. Chromatogr. A 1097 (2005) 138

[8] M. Farre, J. Ramon, R. Galve, M.P. Marco, D. Barceloa, Environ. Sci. Technol. 40 (2006) 5064.

[9] V.K. Balakrishnan, K.A. Terry, J. Toito, J. Chromatogr. A (2006). Available Online at www.sciencedirect.com.

[10] N.T. Malintan, M.A. Mohd, J. Chromatogr. A 1127 (2006) 154.

[11] M. Kotoucek, J. Skopalova, K. Michalkova, Anal. Chim. Acta 353 (1997) 61.

[12] T.A.M. Msagati, J.C. Ngila, Talanta 58 (2002) 605.

[13] T.G. Diaz, A.G. Cabanillas, M.I.A. Valenzuela, F. Salinas, Analyst 121 (1996) 547.

[14] P.J. Gemperline, J.H. Cho, B. Baker, B. Batchelor, D.S. Walker, Anal. Chim. Acta 345 (1997) 155

[15] A. Espinosa-Mansilla, F. Salinas, I.D.O. Paya, Anal. Chim. Acta 313 (1995) 103.

[16] C.K. Markopoulou, E.T. Malliou, J.E. Koundourellis, Il Farmaco 59 (2004) 627.

[17] M.T. Muldoon, C.K. Holtzapple, S.S. Deshpande, R.C. Beier, L.H.J. Stanker, J. Agric. Food Chem. 48 (2000) 537.

[18] M.Y. Haller, S.T. Muller, C.S. McArdell, A.C. Alder, M.J.F. Suter, J. Chromatogr. A 952 (2002) 111.

[19] N.V. Eeckhout, J.C. Perez, C.V. Peteghem, Rapid Commun. Mass Spectrom. 14 (2000) 2331.

[20] F. Merino, S. Rubio, D. Perez-Bendito, Anal. Chem. 76 (2004) 3878.

[21] M. Cantero, S. Rubio, D. Perez-Bendito, J. Chromatogr. A 1067 (2005) 161.

[22] T. Saitoh, S. Matsushima, M. Hiraide, J. Chromatogr. A 1069 (2002) 271.

[23] K. Nagashima, F.D. Blum, J. Colloid Interface Sci. 214 (1999) 8.

[24] P. Wängnerud, B. Jönsson, Langmuir 10 (1994) 3542.

[25] A. Fan, P. Somasundaran, N.J. Turro, Langmuir 506 (1997) 13.

[26] M. Thompson, S.L.R. Ellison, R. Wood, Pure Appl. Chem. 74 (2002) 835. 